\title{
UN SAN PATRICIO VERDE CARIBEÑO: LA CELEBRACIÓN DEL 17 DE MARZO EN LA ISLA DE MONTSERRAT
}

\author{
Rosana Herrero-Martín \\ University of the West Indies - Antigua State College \\ (Antigua y Barbuda)
}

Copyright (c) 2010 by Rosana Herrero-Martín. This text may be archived and redistributed both in electronic form and in hard copy, provided that the author and journal are properly cited and no fee is charged for access.

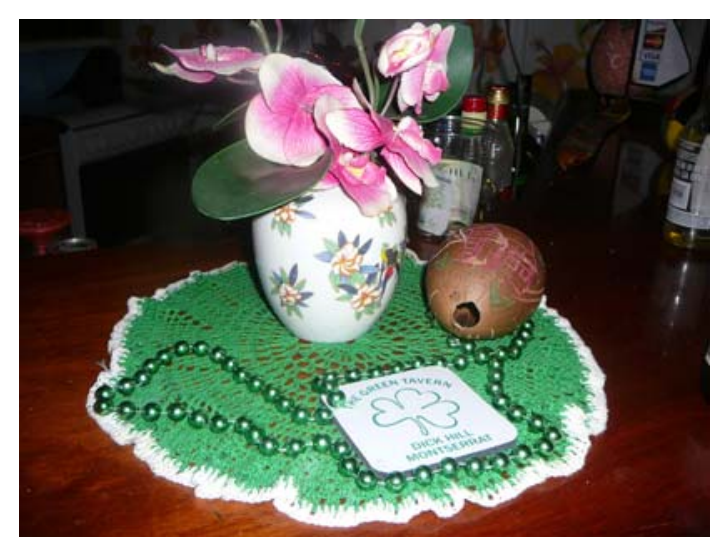

San Patricio caribeño

La isla caribeña de Montserrat es también conocida como la Isla Esmeralda del Caribe, no solo por el exhuberante color verde de su paisaje tropical, sino también por sus vínculos históricos y culturales con Irlanda. Los primeros habitantes de la isla fueron los pueblos indígenas Arawak y Carib. Estos últimos llamaron a la isla Alliouagana ('tierra de la mata pringosa'), tal vez por la abundancia de aloe autóctono. Es a Cristóbal Colón, sin embargo, a quien debe su nombre actual, pues a su paso por la isla en 1493 la bautizó en recuerdo de los montes catalanes, el monasterio y la patrona epónimos. Los primeros asentamientos europeos se remontan a 1632, cuando de la vecina isla de Nevis llegó un contingente de refugiados católicos irlandeses, cuyo credo no era bienvenido en otras colonias británicas del Caribe, de mayoría protestante. Así mismo y simultáneamente, a Montserrat llegó también mano de obra irlandesa voluntaria con contrato de aprendizaje (indentured servants), en su mayoría procedente del Condado de Cork, y en menor medida de Clare, Donegal, Galway, Tipperary, Waterford, Westmeath y Wexford, germen de la futura plantocracia azucarera de la isla. Montserrat fue además el vertedero penal de muchos prisioneros políticos y militares irlandeses, por orden de Cromwell tras su victoria en Drogheda en 1649. Allí Cromwell desterró también a todo aquel irlandés que representara una carga para las arcas públicas, ya fueran huérfanos, viudas o vagabundos. Un censo de 1678 muestra que más de la mitad de la población de la isla eran irlandeses (unos 1900), y el resto de origen inglés, escocés y africano. No resulta pues sorprendente, que el elemento irlandés haya ejercido la influencia más notable en el desarrollo cultural de Montserrat, aun visible hoy en día.

El elemento irlandés está presente, por ejemplo, en el sello en forma de trébol verde que se estampa en el pasaporte del visitante y aparece grabado en la fachada de la Casa del Gobierno (Government House), así como en el escudo nacional, en cuyo blasón se representa a Erin (personificación feminina de Irlanda) portando una cruz y un harpa. El legado 
irlandés está también muy presente en los topónimos montserratinos (Sweeney's Well, Harris Village, Potato Hill, Cork, Kinsale), en los nombres de las familias propietarias de antiguos ingenios o haciendas azucareras (Farrel, Riley, Dyer, Molyneux, Lee), así como en los apellidos de los lugareños comunes (Allen, Daley, Roche, Carty, Kirwan, Skerret, Lynch, O’Garro, Cabey, Brade, Murraine, etc.).

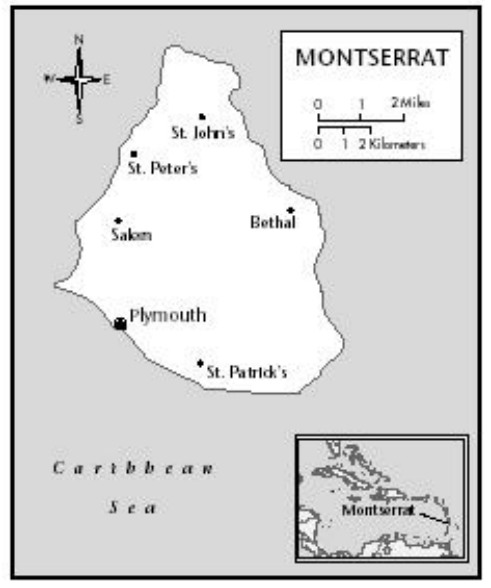

El plato nacional de la isla recibe el nombre de agua de cabra ('goat water') y está directamente emparentado con el cocido irlandés ('Irish stew'). La popular danza folclórica isleña del Bam-chick-a-lay, también se cree que tiene su origen en el zapateado irlandés (Irish step dance). El inglés que se habla en la isla está teñido de acento irlandés (Irish brogue), y durante la semana de fiestas de San Patricio la gente sigue vistiendo de riguroso verde, tal y como marca la tradición.

Montserrat es el único país del mundo, además de Irlanda, donde el día de San Patricio (17 de marzo) es fiesta nacional. Durante toda una semana el calendario isleño se viste de fiesta para celebrar la riqueza cultural autóctona afro-irlandesa, así como para conmemorar una famosa insurrección de esclavos africanos contra la plantocracia azucarera irlandesa de la isla que tuvo lugar un 17 de marzo de 1768, y que fue fraguada aprovechando las distracciones festivas de los patronos. Sin embargo, alguien dio el chivatazo, y la rebelión terminó con el ahorcamiento público de nueve esclavos promotores de la misma. Aun hoy en día continúa el debate sobre quién pudo haber sido el traidor. La esclavitud no se aboliría en Montserrat hasta 1834 y el cruento episodio sirvió para desacreditar el mito existente sobre la benevolencia y solidaridad de los patronos irlandeses, sabedores y sufridores en carne propia de la opresión británica.

Entre las actividades festivas de la semana de San Patricio en Montserrat, destacan la tradicional cena de San Patricio en el Centro Cultural de la isla, recientemente inaugurado por Sir George Martin (productor de los Beatles y mecenas de los emblemáticos estudios musicales AIR Studios Montserrat devastados tras el paso del Huracán Hugo en 1989), quien para la financiación de la construcción del edificio organizó un selecto recital en el Royal Albert Hall de Londres en el que actuaron grandes artistas que habían grabado en Montserrat sus álbumes, entre otros Paul McCartney, Mark Knopfler, Elton John, Sting, Eric Clapton y Midge Ure, y sacó a la luz una edición limitada de quinientas litografías de la partitura de "Yesterday"; misa católica; desayuno criollo; conferencia plenaria y exposición sobre el legado irlandés en la isla; el maratón de la libertad ('Freedom Run') desde Cudjoe Head hasta Salem Park; ruta de pubs que arranca desde el Wide Awake Bar de Garry Moore; competición de calypso; festival de cometas; recreación ambiental de la época de la esclavitud dentro del recinto ferial de Festival Village, con muestras de la tradición gastronómica (bacalao salado, boniato), musical (fusión de ritmos, pasos de baile e instrumentos como el banjo, la armónica, el triángulo, el 'shak shak', y los tambores metálicos o 'steelpan'), lúdica (peonzas, el juego del 'Zig Zag Zaggett' - parecido a las canicas pero con semillas de anacardo), oral (cuentos, leyendas del repertorio sincrético de la isla) y performativa (coloridas mascaradas de disfraces tradicionales que se caracterizan por sus estampados de llamativas rayas o flores, lazos de colores, campanillas, espejitos, látigo en mano, máscara, bombachos y toca alta en forma de mitra obispal a juego, así como por personajes muy queridos como los zancudos Miss Goosey y Moco Jumbie, y John Bull).

Al igual que Irlanda, Montserrat ha sufrido muchas penurias durante su historia, en especial durante su historia más reciente. En 1989 fue devastada por el Huracán Hugo y en 1995 el volcán Soufriere Hills entró sorprendentemente en erupción tras toda una vida adormilado, provocando el desahucio de gran parte del sur de la isla, incluida su capital, 
Plymouth (la Pompeya de los tiempos modernos), y la villa de festejos (Festival Village), ubicada hasta entonces en la parroquia de St. Patrick's. Su población se ha visto en consecuencia drásticamente diezmada,

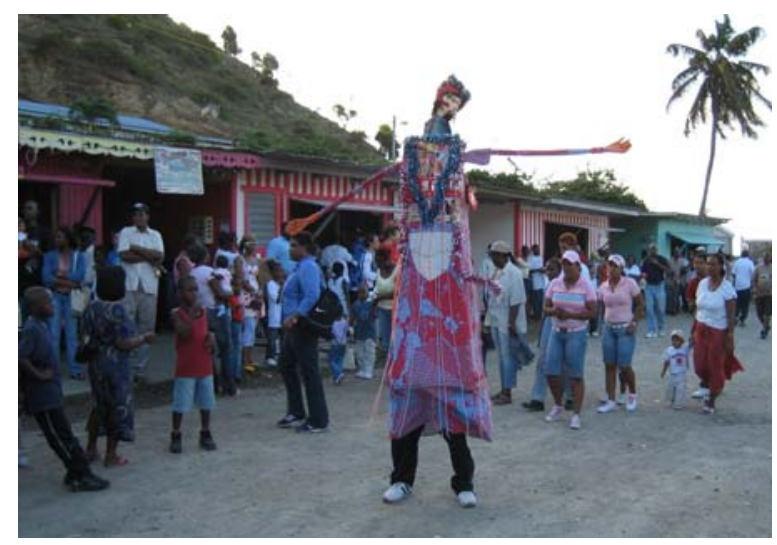

Miss Goosey pasando de 13000 habitantes antes de 1989 a 3000 tras la erupción de Soufriere Hills en 1995. En la actualidad los 6000 pertinaces residentes que la habitan han continuado fieles a la cita del 17 de marzo en otro recinto festivo habilitado en las inmediaciones de Little Bay (noroeste de Montserrat), donde también se concentra el proyecto de nuevo núcleo urbano para la isla.

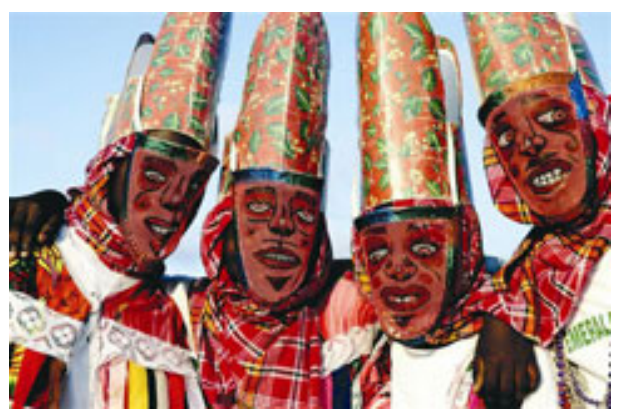

Mascarada tradicional

Rosana Herrero-Martín is Doctor Europeus in Theatre and Performative Studies (University of Salamanca, Spain); she holds a M.A. in Anglo-Irish Literature and Drama (University College Dublin, Ireland), and a M.A. in Publishing Studies (Instituto de Postgrado, Santillana Editores \& Universidad de Salamanca). She has written the book The Doing of Telling on the Irish Stage: A Study of Language Performativity in Modern and Contemporary Irish Theatre (Frankfurt: Peter Lang, 2008). She has worked as Spanish lecturer in Colby College (Maine, USA), Instituto Cervantes, University of Bremen, University of Oldenburg (Germany), and presently she is Spanish Lecturer appointed by the Spanish Agency of International Cooperation at Antigua State College and University of the West Indies. 